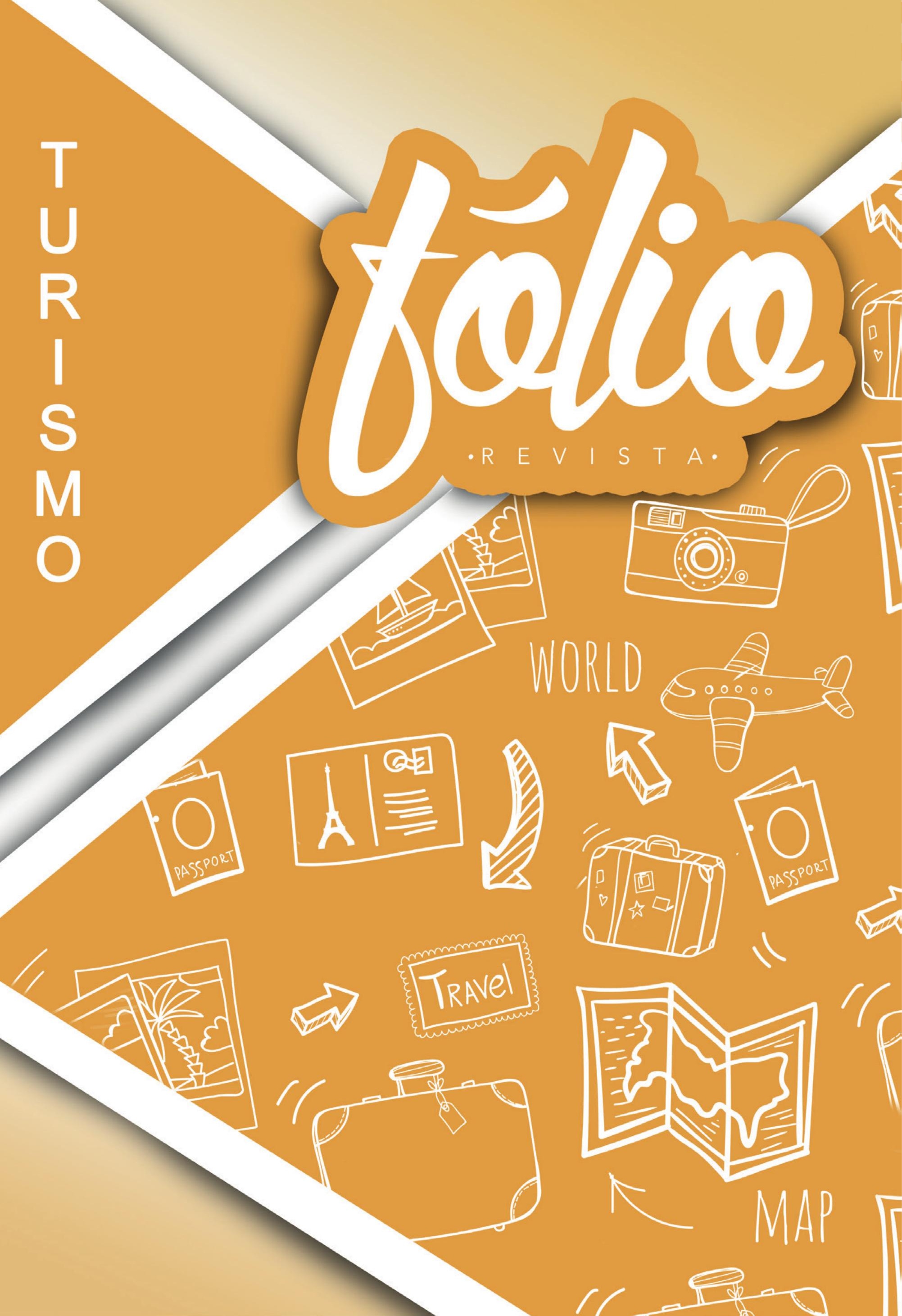




\title{
A capacitação de novos colaboradores com apoio tecnológico: uma proposta para a franquia $\mathrm{Cl}$ Blumenau
}

\author{
Prof. Eddy Ervin Eltermann ${ }^{1}$ \\ Tecnóloga Catarina Roese Alves ${ }^{2}$
}

\section{Resumo}

O presente estudo foi desenvolvido como parte integrante de uma pesquisa sobre tecnologia aplicada à agências de viagens. O objetivo central do projeto foi propor a capacitação de colaboradores pelo uso de ferramentas tecnológicas com intuito de acelerar o aprendizado e fomentar o uso dos materiais informativos da Academia Cl, visto que, apesar da gama de conteúdos, a sua utilização tem se tornado pouco atrativa para os colaboradores. Nesse sentido, buscou-se, inicialmente, compreender os principais autores relacionados aos temas por meio de uma pesquisa bibliográfica pautada nos temas: turismo, agenciamento, capacitação ou treinamento de pessoas e o uso de tecnologias, dentre eles Beni (2001), Rejowsky (2002), Braga (2008), Hall, Cooper e Trigo (2011), bem como, Chiavenato (2010), Cruz e Oliveira (2013) e Wendel (2015). Optou-se também pela pesquisa documental, procurando, dessa forma, elucidar os questionamentos sobre os documentos relacionados ao processo de capacitação na empresa. Partiu-se de uma abordagem qualitativa, com coleta de depoimentos de colaboradores e, a partir disto, buscou materializar as ações a partir da criação de um aplicativo de celular que pode ser utilizado em quaisquer momentos. Nesse sentido, procurou-se desenvolver telas de aprendizado com base em um quiz diário, acessado pelas chefias e, a partir da tomada de decisões destas, podendo ser utilizado como ferramenta de promoção daqueles que se destacam nos processos de aprendizado.

Palavras-chave: Agência de Viagens. Capacitação de novos colaboradores. Tecnologia. Cl Blumenau.

\section{Abstract}

The present study was developed as part of a research on technology applied to travel agencies. The central objective of the project was to propose the training of collaborators for the use of technological tools to accelerate the learning and to promote the use of information materials of the $\mathrm{Cl}$ Academy, since, despite the range of contents, its use has become unattractive for employees. In this sense, we initially sought to understand the main authors related to the subject by means of a bibliographic research based on themes: tourism, agency, training or training of people and the use of technologies, among them Beni (2001), Rejowsky (2002), Braga (2008), Hall, Cooper and Trigo (2011), as well as, Chiavenato (2010), Cruz e Oliveira (2013) and Wendel (2015). A research on documents was also chosen as a method, thus seeking to elucidate the questions about the documents related to the training process in the company. It was based on a qualitative approach, with the collection of statements from employees and, from this, sought to materialize the actions from the creation of a mobile application (APP) that can be used at any time. In this sense, we tried to develop learning screens based on a daily quiz, accessed by managers and, from the decision making of these, to be used as a promotion tool for those who succeed in learning processes.

Keywords: Travel agencies. Training of new employees. Technology. Cl Blumenau.

1 Formado em Turismo e Hotelaria e pós graduado (lato sensu) em Turismo: Planejamento, Gestão e Marketing, pela UNIVALI e Mestre em Educação pela UNISUL. É professor do Instituto Federal Catarinense (IFC), Campus Brusque.

2 Formada em Tecnologia em Gestão de Turismo pelo Instituto Federal Catarinense (IFC), Campus Avançado Sombrio e Acadêmica do Curso de Licenciatura em Artes Visuais pela Uninter. É agente de viagens na Cl Intercambio e Viagens de Blumenau. 


\section{Introdução}

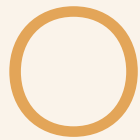

turismo, fenômeno que se desenvolve mundialmente, tem sua rede de articulação e sua necessidade de intermediação representada por vários entes dentro da cadeia produtiva, ou seja, para que o turismo execute sua função, uma série de outros setores devem estar em sintonia e subsidiando seu funcionamento. Trata-se, portanto, de uma relação com hotéis, restaurantes, companhias aéreas, seguradoras, locadoras de veículos, entre outros.

Nesse contexto, as agências de viagens, desde o início de suas operações, deram suporte como intermediadores dos serviços turísticos, promovendo o dinamismo e a profissionalização do setor. Assim, perceber a relação íntima entre o agenciamento e o desenvolvimento do turismo é também perceber toda uma relação de amadurecimento da atividade.

Com isso, ainda que se debatam os processos de desintermediação e reintermediação através das agências on line, bem como, todo o debate que se deu sobre o fim das agências de viagens, com o advento da internet no final dos anos 1990, percebe-se que, atualmente, elas ainda são parte evidente do mercado e nele se configuram como ferramentas importantes na engrenagem do turismo. A internet parece ter se transformado num novo alicerce que pode otimizar os processos e, em alguns momentos, contribuir para a dinâmica da produtividade do setor.

Dessa forma, um dos elementos importantes do dinamismo das novas tecnologias é a possibilidade de se propor capacitações rápidas, assertivas e eficazes para o processo de aprendizado sobre as rotinas de trabalho em agências de viagens. Assim, este estudo propõe a criação de um aplicativo de celular que facilita a prática sobre os diversos sistemas, produtos e procedimentos utilizados pela $\mathrm{Cl}$ Blumenau, buscando servir de suporte para os novos colaboradores que ingressem na empresa, diminuindo assim o tempo e os custos de capacitação.

\section{Agências de viagens: história, conceitos, tipologia e mercado de trabalho}

As agências de viagens, parte fundamental do desenvolvimento turístico, têm sua história constituída a partir de iniciativas individuais, as quais acabaram influenciando todo um mercado de formação, adaptação e reestruturação do turismo. Considera-se que, em seus ideais de iniciação de atividade, importantes fatos e pessoas foram decisivas para o fortalecimento e seu definitivo estabelecimento. Conforme relatos históricos, pessoas, organizações ou mesmo empresas, utilizavam os serviços dos 'conhecedores do ofício' referentes a viagens, para então planejarem e detalharem seus roteiros. Neste contexto pode-se mencionar Bernardo de Abreu que em 1840 fundou a Agência Abreu, na cidade de Porto em Portugal, a qual cuidava de passaportes, vistos e passagens de navio para imigrantes para a América do Sul e vendia passagens de trem para o trecho Lisboa/ Porto (REJOWSKI, 2002).

Na Inglaterra, na mesma época, Thomas Cook iniciou trabalhos relacionados ao agenciamento de viagens. Porém, inovou quando organizou a primeira viagem comandada por uma pessoa, assim marcou o início da atividade turística organizada. Para tal, Cook fretou um trem da Midland Railway Company para o trecho de 11 milhas entre as cidades de Leicester e Lougborough com a intenção de levar 570 pessoas para participarem de um congresso antialcoólico. Consta que nesta incursão ele não obteve lucro, pois era membro e vendedor das publicações da entidade filantrópica Harborough Temperance Society promotora do evento. O mesmo ocorreu em outras empreendidas, mas viu a oportunidade de lucrar com a atividade e 1851 fundou a Thomas Cook \& Son em Leicester e em 1865 abriu uma filial em Londres, comandada pelo filho, John Mason Cook (ELTERMANN, TEIXEIRA, 2012).

Além do seu pioneirismo, são creditadas a Cook outras grandes contribuições na organização das viagens e no desenvolvimento do turismo, como por exemplo: criação do Handbook of the trip, primeiro itinerário descritivo de viagem preparado de forma profissional para uso dos turistas em 1845; organização de uma viagem para cerca de 165 mil excursionistas de Yorkshire à Primeira Grande Exposição Universal no Hyde Park em Londres, em 1851; realização de uma viagem 
de volta ao mundo com duração de 222 dias para um grupo de nove pessoas, em 1872; criação do cupom de hotel (antecessor do voucher) em 1867 e da circular note (antecessora do Traveller Check) em 1874 (REJOWSKY; PERUSSI, 2008).

Em razão das diversas iniciativas promovidas, Thomas Cook é reconhecido como o primeiro agente de viagens profissional. Oliveira (2005, p.30) cita que: "Thomas Cook nasceu em 1808 e morreu em 1892. No ano de sua morte, a agência Thomas Cook \&Son possuía 84 escritórios e 85 agências no exterior empregando 1.700 pessoas. [...] é considerado "o pai do turismo" e reverenciado pelos agentes de viagens em todo o mundo [...]". Após meados do século XIX, pode-se dizer que houve uma grande proliferação de agências, especialmente na Europa.

Na Alemanha, na cidade de Breslau, hoje pertencente à Polônia, Stangem fundou a primeira agência de viagem em 1863. Na Itália, em Milão, Massimiliano Chiari fundou uma agência para recepcionar os turistas estrangeiros, em 1871 e na França, na cidade de Lyon foi fundada a primeira agência de viagem em 1873, por Alphonse Lubin. Merece destaque a fundação da agência La Compgnie dês Wagons-Lits, na Bélgica, com foco na comercialização de bilhetes ferroviários, em 1876 na Bélgica. (REJOWSKI; PERUSSI, 2008). Esta empresa é reconhecida mundialmente e opera até os dias atuais sob o nome de Carlson Wagonlit Travel. A primeira agência de viagem americana surgiu em 1898, em Saint Augustine, Flórida e chamava-se "Ask Mr. Foster". O nome veio em função de um residente local que conhecia todos os horários dos trens e quando alguém precisava de uma informação em relação a partidas e chegadas, os locais respondiam: "ask Mr. Foster". Outro caso data de 1850 quando Henry Wells e mais dois amigos William Fargo e John Butterfield fundaram a American Express Company, a empresa oferecia um serviço expresso de transportes de valores, bens e mercadorias, que mais tarde agregou também serviços financeiros. Foi apenas no final da década de 1890 que a empresa agregou os serviços de viagens e sucedeu a uma época de expansão internacional devido aos seus negócios em outros países como na Inglaterra e na França (IKEDA, 1993).
No Brasil, no início do século XX, surgiram algumas empresas especializadas na venda de passagens de navio. Registra-se que em 1904, Charles Miller (o introdutor do futebol no país), passou a dirigir a agência Miller do seu tio, que representava a Royal Mail Lines - empresa de transporte marítimo que oferecia linhas entre as Américas e Europa e que transportou muitos brasileiros para a Europa e trouxe muitos imigrantes para o Brasil. Na mesma época no Rio de Janeiro a família Cinelli, ingressava no setor. As "casas" como ficaram conhecidas as empresas que atuavam neste tipo de comércio surgiram, a exemplo da Casa Aliança, a Casa Bernardo, a Casa Branco e Expresso Internacional fundada na segunda década do século XX. Antes mesmo desta época, em Salvador, Manoel José do Conde abriu uma empresa dedicada a importação e exportação e passou a representar a companhia marítima Lloyd Real Holandês, passando a se dedicar à venda e ao apoio a cargas e passageiros. Não eram exatamente os agentes de viagens de hoje, mas já serviam aos propósitos das viagens desde aqueles tempos (ABAV, 2004).

A primeira agência eminentemente brasileira foi a Agência Geral de Turismo, fundada no ano de 1943, em São Paulo. Com o rápido crescimento do número de agências em todo o mundo, em 1919 foi criada a primeira Federação Internacional de Agências de Viagens - (International Federationof Travel Agencies - IFTA). Todo este crescimento obviamente se deu em função do desenvolvimento do turismo, impulsionado pelas mudanças da sociedade da época, após a Revolução Industrial. As pessoas começaram a migrar para as cidades e trabalhar nas fábricas recebendo salários. O desgastante ritmo de vida nos grandes centros urbanos fazia com que as pessoas passassem a necessitar de períodos de descanso, daí a busca por viagens.

Montejano (2001, p. 125) destaca que as agências são descritas como:

[...] empresas mercantis que, de posse do correspondente título licença outorgado pela Administração Pública, se dediquem profissional e comercialmente em exclusividade ao exercício das atividades de assessoramento, mediação e 
organização de serviços turísticos, podendo utilizar meios próprios na prestação destes ou sendo, na maioria dos casos, agente intermediário entre os prestadores de serviços-hospedagens, transportadores, restaurantes, guias, etc - e os clientes.

Segundo Braga (2008) este segmento do turismo age como um agregador de serviços, modificando em produto turístico os destinos, serviços e equipamentos. Elas interagem no Sistema de Turismo (SISTUR) proposto por Beni (1998), segundo o qual se necessita de equipamentos e serviços para o seu procedimento. Salientando que as agências dependem do mercado para atuarem, de demanda para comercializarem seus pacotes e ainda atuam como distribuidoras do turismo, fazendo com que aconteça a conexão em todas as partes do sistema.

Assim, as agências possuem como principais funções promoção, organização e serviços vinculados a transporte acomodação e alimentação (TORRE, 2003), as quais são descritas na Lei 12.974 de 15 de maio de 2014 que dispõe sobre as atividades das Agências de Turismo. Elas podem ser classificadas em Agências de Viagens Detalhistas ou Minoristas, que segundo Ruiz, Armand e Cobreros apud Braga (2008) como responsáveis pela venda ao consumidor final dos produtos das Agências Maioristas, que por sua vez comercializam seus produtos para as Agências Minoristas.

Já para Petrocchi e Bona (2003, p. 152) existem outros três tipos de agências:

Agências Corporativas, que vendem as passagens aéreas e reservas de hotéis para organizações e executivos; as Agências Generalistas, que por sua vez vendem todos os tipos de produtos turísticos; e, por fim as Agências Especializadas, apresentando uma segmentação de mercado específica para a venda de seus produtos turísticos.

Assim, o mercado das Agências de Viagens, como já descrito por Petrocchi e Bona (2003, p.13) no início do século, chega à contemporaneidade em um período de constantes mudanças que afetam toda a dinâmica de mercado, gerando dúvi- das sobre seu posicionamento e dinamizando a necessidade constante de adaptação e construção de novas possibilidades de oferta de produtos. A cada dia surgem novos consumidores, cada vez mais exigentes à procura de novas atividades, nascendo assim novas segmentações turísticas para atender um público tão seleto. E nessa sociedade da informação, garantir uma resposta imediata a qualquer questionamento dos clientes é fundamental para a construção de uma relação de confiança com aquele que oferece o produto a ser comercializado.

\section{Tecnologia e capacitação: o aprimoramento de novos colaboradores como forma de melhora de desempenho em empresas}

As agências de viagens operam, constantemente, com uma série de informações, sistemas, operações e adequações em função da dinâmica do mercado turístico, de todas as suas nuanças e das constantes alterações dinamizadas pelo mercado. Há que se considerar que o mercado de agenciamento sempre esteve diretamente ligado à tecnologia, fazendo com que, dentre outros, sistemas como os Sistemas de Distribuição Global (GDS) fossem desenvolvidos para favorecer a comercialização de produtos turísticos no mundo. Os sistemas de distribuição são de suma importância para o proceder de uma agência de viagem, o uso da internet, dos dispositivos eletrônicos e mídias sociais têm proporcionado o avanço de muitas empresas.

A atualidade já é dependente do uso da internet e seus meios, as informações transitam em alta velocidade e, sendo assim, empresários de todos os ramos, incluindo o turístico, aderiram ao uso das novas tecnologias para sustentarem seus negócios e lhes proporcionar um maior rendimento econômico. Na perspectiva de profissionalizar o turismo, diminuindo as condições instáveis para sua realização, a intermediação de sua atividade visa gerar um fluxo contínuo e organizado.

Assim, um dos setores primordiais na distribuição e profissionalização do turismo são as 
agências de viagens, responsáveis pela interlocução entre produtos e serviços e fundamentais na relação com clientes e fornecedores. Deste modo as empresas, como forma de ultrapassar as barreiras que se colocam para o futuro das organizações, devem estar sempre atualizadas e para serem competitivas e destacarem-se no mercado, podendo utilizar a vantagem de uma força de trabalho bem preparada. Para tal, necessitam manter um quadro de colaboradores aptos a operacionalizar esta vasta gama de sistemas e informações, bem como, a qualidade no atendimento. Oliveira; Cruz (2013) recomendam o treinamento e o desenvolvimento de habilidades para que desenvolvam suas tarefas de forma eficaz e que thes permita crescer dentro da organização. Quanto ao treinamento Bohlander e Snell (2015) elencam que o termo muitas vezes é usado para descrever praticamente qualquer esforço da empresa para estimular o aprendizado de seus colaboradores. Relatam ainda que alguns especialistas, entretanto, distinguem o treinamento focado e orientado para questões relativas ao desempenho no curto-prazo e desenvolvimento mais voltado no sentido ampliar as habilidades dos indivíduos para futuras responsabilidades.

Já para Chiavenato (2010) treinamento é "[...] o processo educacional aplicado de maneira sistemática e organizada pelo qual as pessoas aprendem conhecimento, atitudes e habilidades em função de objetivos definidos". Nesse sentido, Oliveira e Cruz (2013) relatam que algum tempo atrás, o treinamento envolvia a preparação de atividades, visando ao conhecimento técnico sobre a realização destas, porém na atualidade vem se destacando a importância para o desenvolvimento de competências comportamentais, gerando a possibilidade de crescimento para quem busca novos conhecimentos e desenvolvimento de habilidades.

A necessidade de treinamento pode ser apontada pela empresa, por algum setor ou pelos próprios colaboradores, assim, esta empresa tem força positiva no processo, mas a responsabilidade sobre o aprendizado e carreira pessoal ainda é do indivíduo (OLIVEIRA; CRUZ, 2013). Visando a redução da necessidade de treinamento, Boog (1994, p.56) esclarece que este deve: "ser imediatamente aplicável e estar ajustado à realidade/necessidade da empresa; utilizar multiplicadores internos; incentivar o autodesenvolvimento; e, ainda deve ser avaliado sistematicamente". Para Pio (2015), o diferencial está nos vários tipos de treinamento, ou seja, o primeiro é o de integração visando à adaptação do sujeito à organização; em seguida o técnico-operacional, que trata da capacitação do indivíduo para desempenho das tarefas específicas que deve realizar; o treinamento gerencial trata do desenvolvimento da competência técnica administrativa; e, por fim, o comportamental que envolve as relações interpessoais no contexto do trabalho.

Complementando a classificação, Chiavenato (2010) nos ensina que são diversas as técnicas de treinamento como leitura, instrução programada, treinamento em classe, computer-based training, e-learning e estas ainda podem ser classificadas quanto ao uso, ao tempo e ao local, e se baseiam na aplicação da teoria de aprendizagem. Nesta mesma vertente nos diz que o treinamento pode promover alteração comportamental das pessoas por meio de quatro tipos de mudanças: transmissão de informações, desenvolvimento de habilidades, de atitudes e de conceitos e compõem-se por quatro etapas: diagnóstico, desenho, implantação e avaliação. Ainda, para o autor a tecnologia enriquece o processo com o uso de recursos audiovisuais, teleconferência, comunicações eletrônicas, correio eletrônico e multimídia. (CHIAVENATO, 2010).

Pode-se ainda, descrever vários os tipos de treinamento além do presencial ou em serviço, como palestras, workshops e seminários, porém o treinamento à distância com o uso de recursos e-learning como podcasts, webmetings gravados ou ao vivo com interação na plataforma no sistema Intranet, aplicativos, entre outros, tem como vantagem a remoção de barreiras como tempo/ espaço, gerando a possibilidade de o próprio treinando ter o controle sobre o início, manutenção e ritmo de sua aprendizagem. Estes recursos, chamados ambientes digitais de aprendizagem são sistemas computacionais disponíveis na internet e permitem integrar múltiplas mídias e recursos, apresentar informações de maneira organizada, desenvolver interações entre as pessoas, elabo- 
rar e socializar informações visando atingir determinados objetivos.

As atividades se desenvolvem no tempo, ritmo de trabalho e espaço em que cada participante se localiza, de acordo com objetivo específico e um planejamento prévio. Almeida (2003) classifica os ambientes digitais de aprendizagem como suporte de Educação à Distância (EaD) e seus termos frequentemente aplicados como equivalentes seja em ensino formal, atividades livres, treinamentos ou formação continuada são educação a distância, online e e-learning, porém cada um possui especificidades.

Somente para contextualizar, Educação à Distância refere-se à distância física entre professor e aluno e pode utilizar diversos meios (correspondência postal ou eletrônica, rádio, televisão, telefone, fax, computador, Internet, entre outros) e técnicas que possibilitem a comunicação. Educação on line é a modalidade realizada via internet e, consequentemente, o chamado, e-learning é uma modalidade de educação a distância com suporte na Internet que se desenvolveu a partir das necessidades de empresas relacionadas com a capacitação de seus funcionários.

A modalidade e-learning tem suas práticas centradas na seleção, organização e disponibilização de recursos didáticos hipermidiáticos. Ainda segundo Almeida (2003), o e-learning originado no espaço corporativo, na perspectiva de treinamento, começa a incorporar práticas para desenvolver competências por meio da interação e colaboração entre os aprendizes. Desta forma, tem sido considerada a solução para superar as dificuldades de tempo, deslocamento e espaço físico que comporte muitas pessoas reunidas e está sendo apontado como a tendência atual de treinamento, aprendizagem e formação continuada no setor empresarial.

Nesse sentido, tendo em vista a redução de custos com a comunicação interna e visando obter maior interação entre seus colaboradores, as empresas estão apostando no uso da Intranet Corporativa como ferramenta para alcançar os objetivos mais rapidamente e ainda e obter maior interação entre seus colaboradores. Trata-se de uma rede que se utiliza de tecnologia e da infraestrutura da internet a fim de centralizar as informações inter- nas das empresas, facilitando o acesso e o compartilhamento desse conteúdo por pessoas autorizadas (WENDEL, L., 2015). Desta forma, alguns programas de treinamento são disponibilizados dentro das plataformas Intranet e utilizados como base da gestão do conhecimento da empresa.

Dessa forma, o treinamento deve ser visto como um investimento, o qual pode agregar valor tanto à empresa quanto ao colaborador, pois ao investir no colaborador a empresa ganha em produtividade e excelência em seus serviços prestados ao consumidor, da mesma forma em que possibilita o desenvolvimento pessoal.

\section{Métodos e procedimentos científicos}

O conhecimento científico é, de forma geral, primordial ao desenvolvimento de qualquer sociedade na contemporaneidade. Promover o desenvolvimento de uma demanda relacionada ao conhecimento é estabelecer parâmetros que possam servir como elementos que provam, a partir de uma série de métodos, a maneira de validar um conhecimento. Nesta pesquisa, partiu-se da premissa de utilização do método indutivo, o qual se configura por analisar um fato a partir da particularidade ( $\mathrm{Cl}$ Blumenau) e propor ou teorizar sua possibilidade de validação como conceito na totalidade ou universalidade (possivelmente em todas as $\mathrm{Cl}$ do Brasil ou em todas as agências do ramo).

Nessa perspectiva, pode-se afirmar que:

Nesse método, parte-se da observação de fatos ou fenômenos cujas causas se deseja conhecer. A seguir, procura-se compará-los com a finalidade de descobrir as relações existentes entre eles. Por fim, procede-se à generalização, com base na relação verificada entre os fatos ou fenômenos (GIL, 2008, p. 10-11).

Dessa forma, em se tratando do presente estudo, entende-se que a formulação de um conhecimento a partir da observação e da coleta de depoimentos com os colaboradores da Cl Blumenau pode formar resultados que, consequentemente, constituem possibilidades de desenvolvimento de conceitos para formar universalidades, pois se 
entende que existe a possibilidade de aproximação das dificuldades com colaboradores de outros estabelecimentos similares.

Quanto à abordagem, pode-se afirmar que se constitui como qualitativa, pois se trata de uma proposta no qual os depoimentos dos colaboradores podem auxiliar na formação de conceitos amplos e, nestes depoimentos, a riqueza da informação se constitui no conteúdo e na aproximação com a problemática a partir de um ponto de vista mais humanista. Constitui-se, portanto, numa relação em que o conteúdo e seus pormenores podem ser mais relevantes que a quantificação dos resultados, sem ainda desmerecer sua utilização em outros momentos (SEVERINO, 2000).

Outra forma de pesquisa se deu a partir da análise documental, a qual trata da utilização de documentos que contribuem para formar determinantes do conhecimento da área. Estes, que são denominados 'literatura cinzenta', são documentos não convencionais que podem ser encontrados em catálogos, folhetos, jornais empresariais, e até mesmo em páginas comerciais da internet ou em publicações de publicidades de produtos, e podem conter dados importantes para a pesquisa que está sendo elaborada (MATTAR, 2008). Nessa perspectiva, o presente estudo se pautou em uma série de documentos da empresa $\mathrm{Cl}$, sejam eles referentes ao treinamento, que englobam todas as lojas, seja na construção de seu histórico e de outros que relacionam informações específicas à loja de Blumenau.

Pode-se afirmar, também, que o presente estudo se constitui como uma pesquisa exploratória, a qual tem como característica desenvolver, modificar e esclarecer conceitos e ideias, a partir de um olhar que também interfere no assunto e na conduta da pesquisa, haja vista que o estágio interfere diretamente na dinâmica da empresa. Este tipo de pesquisa/ estudo engloba, dentre outras possibilidades levantamentos bibliográficos e documentais, entrevistas não padronizadas e estudos de caso (GIL, 2008).

Ainda, procurou-se utilizar uma coleta de depoimentos para servir de instrumento de compreensão das possibilidades de início de trabalho na $\mathrm{Cl}$, buscando elucidar a maneira como os colaboradores iniciaram sua possibilidade de trabalho na empresa. Nesse sentido, quanto à entrevista, Severino (2007, p. 124) a define como uma "[...] técnica de coleta de informações sobre um determinado assunto, diretamente solicitadas aos sujeitos pesquisados. Trata-se, portanto, de uma interação entre pesquisador e pesquisado".

Para o autor Triviños (1987, p. 123), a coleta de depoimentos se condiciona aproximando aos conceitos da pesquisa exploratória, pois há uma relação que não implica na ausência do cientista, pois este afirma que ao pesquisar, há que se procurar em não induzir as pesquisas ou depoimentos, "[...] mas isso não significa que o pesquisador assuma uma postura neutra; ao contrário, ele é sujeito participante da pesquisa, diretamente implicado na relação pesquisador-pesquisado".

Trata-se ainda, de uma pesquisa semiestruturada, na qual o pesquisador propõe um caminho de pesquisa, mas procura não trabalhar com um questionário rígido, e sim, com possibilidades que possam organizar a conduta das questões de acordo com o caminhar dos depoimentos, explorando o melhor que se possa de cada uma das possibilidades de respostas dos entrevistados (SEVERINO, 2007). Já sobre a coleta dos depoimentos, esta aconteceu entre 20 de outubro e 02 de novembro de 2017, nas dependências da $\mathrm{Cl}$ Blumenau ou em questionamentos gravados e enviados por meio da ferramenta denominada Whatsapp. Procurou-se deixar o entrevistado o mais à vontade possível, podendo este escolher a melhor forma de entrevista. Quanto aos questionamentos, apesar de um roteiro pré-disposto, partiu-se sempre do pressuposto de aproveitar aquilo que os entrevistados tinham a dizer sobre sua experiência em sua entrada na $\mathrm{Cl}$ Blumenau e, a partir desta, buscar ideias que pudessem auxiliar na experiência cada vez mais harmoniosa de novos colaboradores.

\section{O aplicativo como ferramenta educacional: resultados de pesquisa e proposta para a Cl Blumenau}

A construção da ferramenta se consolida como uma proposta de capacitação para a $\mathrm{Cl}$ Blumenau, contudo, há que se salientar que a empre- 
sa já oferece, por meio da Academia Cl, na Intranet, capacitação para os funcionários, seja pelos vídeos disponibilizados, seja pela plataforma de documentos que são ofertados como forma de conhecimento para quem está na empresa. Contudo, o excesso de informação, muitas vezes, dificulta a busca imediata, especialmente em situações nas quais o cliente está à frente do colaborador, necessitando de respostas imediatas aos seus questionamentos, pois promove a credibilidade na informação prestada.

Nesse sentido, muitos colaboradores buscam a informação em um mundo elevado de conteúdos e têm dificuldade em encontrar, bem como, a dinâmica de utilização é, muitas vezes, desestimulada pelo excesso de conteúdo para a atuação de primeiro momento. Há que se destacar que o excesso de informações não é prejudicial, mas em se tratando de uma geração acostumada a conteúdos rápidos e dinâmicos, a leitura de procedimentos mais específicos poderia ser feita a partir do momento em que os conhecimentos básicos já foram assimilados.

Dessa forma, apresentam-se alguns dados referentes à pesquisa realizada com os colaboradores da $\mathrm{Cl}$ Blumenau sobre seu processo de iniciação na empresa. Devido ao reduzido número de funcionários, foram realizadas apenas entrevistas semiestruturadas com perguntas abertas. As pesquisas foram realizadas apenas com o setor de atendimento, haja vista que as sócias proprietárias entraram na empresa em um período anterior à implantação dos treinamentos.

Assim, foram questionadas inicialmente qual a idade e o tempo de empresa de cada um dos colaboradores, resultando em sua maioria, exceto um dos colaboradores que já trabalha há 5 anos, em experiências inferiores há 6 (seis) meses e uma faixa estaria entre 20 e 23 anos. Em sequência foi questionada a média de treinamentos realizados nas primeiras semanas de $\mathrm{Cl}$.

"Quando eu comecei a trabalhar na Cl Blumenau, ficou acordado com as minhas chefes que as minhas primeiras 2 (duas) semanas eu ficaria apenas realizando 61 treinamentos, nem me lembro quantos foram, para assim conhecer todos os produtos e posteriormente a isto estaria apto a iniciar atendimentos" (Entrevistado 01).

"Fiz alguns treinamentos de acordo com a ordem sugerida pela Academia, mas aprendi na prática a maioria do que sei. Logo fui colocando em pretica o que aprendia nos treinamentos, assim memorizei com mais facilidade, creio que por semana devem ter sido uns 15" (Entrevistado 02).

"No meu primeiro mês de Cl fui fazendo os treinamentos de acordo com os produtos que eu tinha mais curiosidade. Deve ter uma média de 10 ou um pouco menos, por ai!" (Entrevistado 03).

Quando questionados a respeito dos treinamentos realizados nos últimos meses, constatou-se que nenhum dos colaboradores havia acessado a Academia $\mathrm{Cl}$ em um prazo inferior há 30 dias. Já, referente à escolha dos temas dos treinamentos, os entrevistados responderam da seguinte forma.

"Segui a ordem sugerida, já que conhecia pouco sobre os produtos da $\mathrm{Cl}$ quando comecei" (Entrevistado 02).

"Fiz de acordo o que eu achava mais interessante, pois assim eu tinha bastante motivação para prestar atenção" (Entrevistado 03).

Nas entrevistas e em demais momentos constatou-se que todos os colaboradores da $\mathrm{Cl}$ Blumenau possuem um smartphone. Assim, como teriam a possibilidade de utilizar um dos dois smartphones da loja para entrar com a sua conta e realizar o que se fizesse necessário, entende-se que há a possibilidade de agilidade no processo.

A constante necessidade de adaptação de ferramentas para favorecer o modelo de aprendizagem de novos colaboradores é uma preocupação de empresas em todos os setores, haja vista que quanto mais rápido estiverem aptos à realização de suas atividades, antes trarão resultados para a empresa. Assim, a utilização de novas ferramentas de aprendizagem, ainda que possam gerar custo inicial à empresa, promovem o aumento na velocidade de capacitação, efetividade na manutenção do conhe- 
cimento e o desenvolvimento das habilidades.

Nesse sentido, propõe-se aqui a utilização de ferramentas tecnológicas como auxilio na capacitação de novos colaboradores. A escolha de ferramentas tecnológicas se deu por meio da constatação de que os colaboradores têm intimidade com a tecnologia em geral por estarem acostumados com ela, tendo em vista o perfil jovem dos colaboradores da $\mathrm{Cl}$ Blumenau. Haja vista que todos os colaboradores possuem smartphones, uma plataforma comum já pode ser estabelecida. $\bigcirc$ aplicativo tem uma apresentação simples e limpa, como pode ser visualizado na Imagem 01. Neste primeiro momento são dispostos apenas os atalhos-chave para que não ocorra dificuldade por excesso de informações dispostas em um plano. As abas seguem uma lógica de hierarquia que terá um passo a passo indicativo no primeiro acesso ao aplicativo:

Imagem 01 - Tela inicial do aplicativo

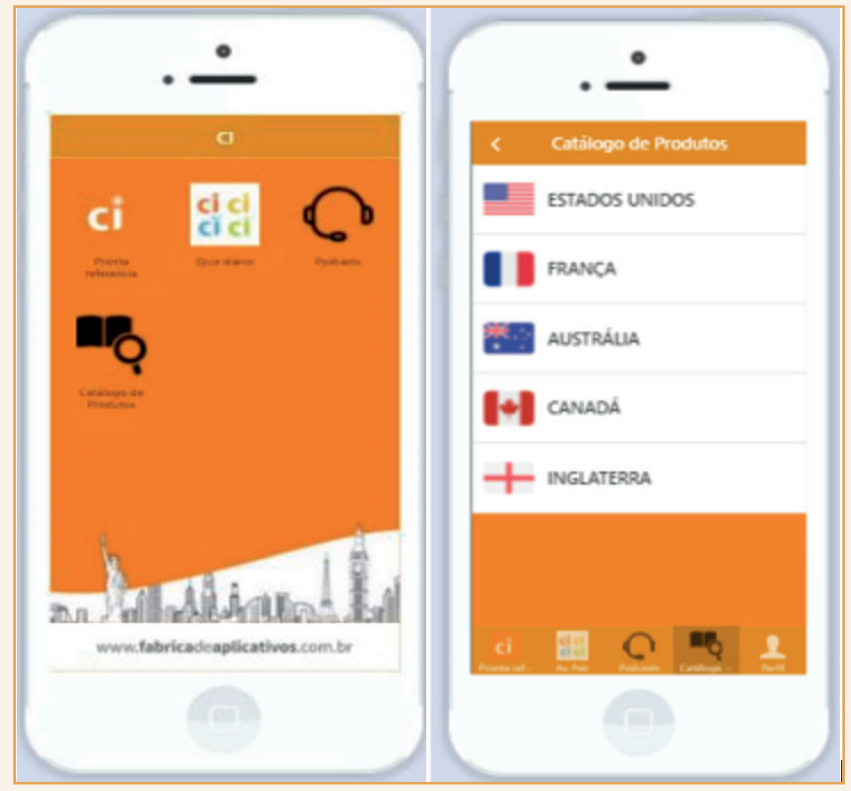

Fonte: Adaptado pelos autores, 2018.

Conforme Imagem 01 (à esquerda), o aplicativo terá três grandes áreas de reunião de informação, são elas: arquivos de prontas referências dos principais produtos para consulta rápida em forma de perguntas e respostas; área de aplicação e verificação dos conteúdos que funcionará em um quiz sobre os temas abordados nos treinamentos anteriores, visando à memorização do conteúdo; e ainda um espaço que funcionaria em conjunto com a Academia $\mathrm{Cl}$, que permita o controle sobre a realização do treinamento, que será um dos requisitos para as recompensas. Outra opção que constará no aplicativo proposto são as opções de treinamentos em áudio que o consultor poderá ouvir em qualquer lugar, até mesmo realizar no trajeto de ida e volta do trabalho.

Ainda, na Imagem 01 (à direita), como se pode visualizar, está disposta a aba do aplicativo referente ao catálogo de produtos de acordo com - país de pesquisa. Em países como a França é importante destacar a presença de programas no local, tais como curso de idioma (francês), cursos profissionalizantes em famosas escolas de gastronomia, entre outros. Nos outros programas, como o de estudo com permissão para trabalho em países como Austrália e Canadá, também serão dispostos de maneira que o acesso se dê de modo fácil e prático. No modo de pesquisa por países, podemos ainda, encontrar, nos Estados Unidos o programa de Au Pair, que tem diversos pré-requisitos, e que demanda uma série de dúvidas quanto à comprovação das horas necessárias, como a necessidade de carteira assinada ou não, crianças com grau de parentesco, entre outros. Para elucidar os questionamentos, expõe-se a tela de pronta referência do programa. Esta tela que funcionaria para todos os produtos da mesma maneira, pré-requisitos para o programa, dúvidas frequentes e peculiaridades do programa.

Imagem 02 - Tela de informações Au Pair

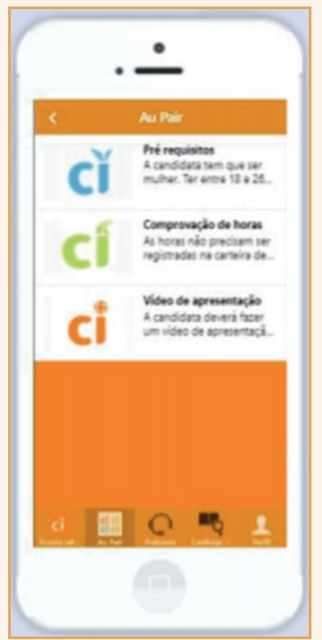

Fonte: Adaptado pelos Autores, 2018 
O esquema de recompensas assim como o incentivo à realização dos treinamentos trarão diversos benefícios à franquia. Um consultor capacitado e bem treinado terá mais argumentos de venda, aumentando a assertividade e a eficácia de finalização de vendas.

O estímulo do colaborador ao uso das ferramentas será realizado por um esquema de recompensas que irá estimular o uso do aplicativo por retorno financeiro. Previamente, para a explanação do esquema de recompensas faz-se necessária uma contextualização sobre as metas e o comissionamento aplicado nos produtos comercializados na agência.

O valor das metas é estabelecido nos contratos de trabalho de cada um dos colaboradores, sendo que estas são estipuladas sobre a somatória do lucro das vendas. A cada meta atingida o percentual de comissionamento aumenta, sendo que também é recebido de acordo com o valor total do lucro das vendas. Sendo que o colaborador, após realizar o treinamento passa a ter o valor total do lucro do produto somado ao valor referencial para sua meta mensal, em casos da não realização do treinamento específico ou expiração da validade de oito meses do treinamento, apenas metade do valor é adicionado ao dito referencial.

Ainda, sendo possível para os superiores da loja acessarem o ranking de pontuação de acertos no quiz, pretende-se promover motivação entre os funcionários para acertar os questionamentos propostos. Dessa forma, constitui-se uma ferramenta de aprendizado que pode parecer, ao colaborador, um interessante jogo de perguntas e respostas, que o faz estudar com um sentimento de que está brincando.

Quanto à classificação e a competição das etapas, o ranking pode ou não ser divulgado para todos os colaboradores, sendo que estes, dependendo do nível de relação que detém, podem competir de maneira saudável. A somatória de somente metade do valor do lucro à meta do colaborador pode ainda gerar economia para os proprietários da franquia, tendo como base que as metas de colaboradores despreparados serão atingidas com menos frequência. Quanto aos custos, ainda que não haja valores específicos para a manutenção, posto que a ideia é que o projeto inicialmente seja utilizado em Blumenau, espera-se que possa servir de modelo para as outras lojas $\mathrm{Cl}$ no Brasil.

\section{Considerações finais}

O mercado e as possibilidades de organização do mundo do trabalho configuram-se, cada vez mais, em dinâmicas nas quais não só a qualidade deve ser atingida e tratada como fator preponderante, mas também a velocidade com a qual se consegue atingi-la. Assim, oferecer um bom produto ou serviço não é mais um diferencial, mas sim, oferecê-lo com velocidade e credibilidade, haja vista o aumento constante da competição corporativa que se estabelece em todas as áreas.

Nesse sentido, em um espaço tão competitivo quanto o mercado de agências de viagens, no qual cada vez mais as ferramentas estão dispostas aos consumidores sem a necessidade de intermediação, mostrar confiança e agilidade pode determinar o sucesso de uma empresa. Assim, cada vez mais a capacitação, a manutenção de bons profissionais, a busca por dinâmicas em processos, a procura por tecnologias que favoreçam o mercado e os processos de preparação de novos colaboradores são alguns exemplos do que as empresas procuram fixar como meta de desenvolvimento.

$\mathrm{A} \mathrm{Cl}$, referência nacional no mercado de intercâmbios, tem em Blumenau uma de suas primeiras franquias no Brasil, a qual se constitui com uma série de conquistas estabelecidas pela experiência gerada na empresa (como franquia) e nas inúmeras lojas espalhadas pelo Brasil. Nesse processo, uma série de informações são dispostas no portfólio da empresa e cada vez mais seus colaboradores têm uma gama de informações acessadas por meio da Academia Cl. Contudo, apesar de toda a gama de informações e do alto número de produtos, muitas vezes o excesso destas informações pode conduzir o colaborador, especialmente os menos experientes, a dúvidas sobre como encontrar informações imediatas e sobre como utilizá-las de forma mais adequada.

Assim, buscou-se, nesta pesquisa, apresen- 
tar uma ferramenta que pudesse atender demandas mais imediatas e estimular o uso de algumas ferramentas de busca numa conduta mais ágil e mais adaptada aos interesses da nova geração. Percebeu-se que a dinâmica de utilização dos documentos da Academia $\mathrm{Cl}$, ainda que completos e interessantes para uma pesquisa ampla, podem determinar falta de dinamismo, de respostas rápidas e impossibilitar a contínua utilização prazerosa dos mesmos. Com isso, procurou-se, portan- to, desenvolver um aplicativo (APP) que pudesse dinamizar a utilização do material, seja ele a partir de um quiz ou oportunizando uma espécie de 'jogo didático'.

Nesse contexto, pretende-se motivar os colaboradores a optarem pela contínua utilização sob forma de lazer ou pela proposta de busca rápida de conteúdos, otimizando o acesso e dinamizando a utilização do aplicativo, dada a condição de se ter uma ferramenta literalmente 'sempre à mão' .

\section{Referências Bibliográficas}

ABAV (Associação Brasileira de Agência de Viagens). Livro comemorativo da Associação Brasileira de Agências de Viagens. 1953 - 2003 - 50 anos de história: lutas e vitórias. São Paulo: ABAV. Março de 2004.

ALMEIDA, M. E. B. Educação a Distância e Tecnologia: contribuições dos ambientes virtuais de aprendizado. IX Workshop de Informática na Escola - WIE - 2003. Disponível em: Acesso em 17 Set 2017.

BARBOSA, A. de S.N.; ALCALDE, E. de A.; DIAS, M. T.; OLIVEIRA, P. Os desafios e possibilidades do treinamento desenvolvimento nas empresas. Três Lagoas MS: Faculdades Integradas de Três Lagoas, 2013. Disponível em: Acesso em: 10 Out 2017.

BENI, M. C. Análise estrutural do turismo. 13. ed. São Paulo: Senac, 1998.

Análise Estrutural do Turismo. Belo Horizonte - MG: Senac, $5^{a}$ edição, 2001.

BOHLANDER, G.; SNELL, S. A administração de recursos humanos. 16a Ed São Paulo/SP: Cengage Learning, 2015.

BOOG; G. G. Manual de treinamento e desenvolvimento. São Paulo: Makron Books, 1994.

BRAGA, Débora Cordeiro. Agências de Viagens e Turismo: Práticas de mercado. Rio de Janeiro: Elsevier, 2008.

BRASIL. LEI No 12.974, DE 15 DE MAIO DE 2014. Dispõe sobre as atividades das Agências de Turismo. Brasilia, DF, Mai 2014. Disponível em www.planalto.gov.br/ccivil_03/_ato2011-2014/2014/lei/l12974.htm> Acesso em 20: Ago 2017 BRASIL.

Ministério do Turismo. Plano Nacional de Turismo 2013-2016. Brasília, DF, 2013. Disponível em: . Acesso em: 30 jun. 2016.

CHIAVENATO. I. Gestão de pessoas. 3. ed. Rio de Janeiro/RJ. Elsevier, 2010. desenvolvimento nas organizações. Revista Científica do ITPAC, Araguaína/TO. v.6, n.2, Pub.2, Abril 2013.

ELTERMANN, E. E.; TEIXEIRA, A. H. Agenciamento e Transportes. 1. ed. Indaial, SC: Uniasselvi, 2012. 229p

GIL, A. C. Métodos e técnicas de pesquisa social. 6ª Ed. São Paulo: Atlas, 2008.

HALL, C. M.; COOPER C.; TRIGO, L. G. G. Turismo Contemporâneo. 1 ed. Rio de Janeiro, RJ: Campus Elsevier, 2011 
IGNARRA, L.R. Fundamentos do Turismo. São Paulo: Pioneira Thomson Lerning, 2001.

IKEDA, Ana Akemi. O Marketing em empresas de pequeno porte e o setor de serviços: um estudo em agências de viagens. São Paulo: FEA/ USP, 1993 (Tese de doutorado).

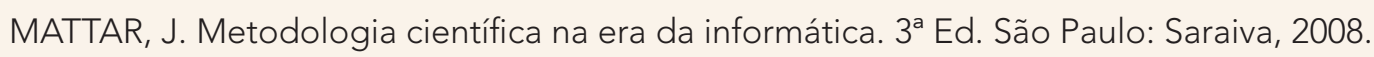

MONTEJANO, J. M. Estrutura do mercado turístico. São Paulo: Roca, 2001.

OLIVEIRA, Antônio Pereira. Turismo e desenvolvimento: planejamento e organização. $5^{\mathrm{a}}$ ed. rev. e ampl. São Paulo: Atlas, 2005.

OLIVEIRA, I. J.; CRUZ, C. A.B. A importância da aplicação do treinamento e desenvolvimento nas organizações. Acesso em: 11 Out 2017.

PETROCCHI, Mario; BONA André. Agências de Turismo: planejamento e gestão. São Paulo: Futura, 2003.

PIO; C. Treinamento e desenvolvimento de pessoas: dois lados da mesma moeda. 2015. Disponível em: < http:// www.rhportal.com.br/artigos-rh/treinamento-edesenvolvimento-de-pessoas-dois-lados-da-mesma-moeda> Acesso em: 10 de Out 2017.

REJOWSKI, Mirian. (org.). Turismo no percurso do tempo. São Paulo: Aleph, 2002.

REJOWSKI, Mirian; PERUSSI, Regina Ferraz. Trajetória das agências de turismo: apontamentos no mundo e no Brasil. In: BRAGA, Débora Cordeiro. (org.). Agências de Viagens e Turismo: Práticas de mercado. Rio de Janeiro: Elsevier, 2008.

SEVERINO, A. J. Metodologia do trabalho científico. 23. ed. rev. e atual. São Paulo: Cortez, 2007. Metodologia do trabalho científico. São Paulo: Cortez, 2000.

TORRE, Francisco de la. Agência de viagens e transporte. São Paulo: Roca, 2003.

TRIVIÑOS, Augusto N. S. Introdução à pesquisa em ciências sociais. São Paulo: Atlas, 1987.

WENDEL, L. Casos de sucesso em Intranet Corporativa. Centro Universitário Salesiano São Paulo, São Paulo/SP. Unisal, 2015. 